\title{
A EVOLUÇÃO DO SARAMPO NO BRASIL E A SITUAÇÃO ATUAL
}

\author{
Carla Magda Allan S. Domingues', Maria Carolina C. Q. Pereira', Elizabeth \\ David dos Santos ${ }^{2}$, Marilda Mendonça Siqueira ${ }^{3}$, Bernardus Ganter ${ }^{4}$
}

O presente artigo sintetiza a evolução do sarampo no Brasil, descrevendo as estratégias adotadas após a implantação do Plano de Eliminação do Sarampo, em 1992, e avalia o impacto alcançado com as medidas adotadas. No ano de 1996 foi detectado um surto de sarampo no Estado de Sáo Paulo e outro em Santa Catarina. No ano de 1997, até a semana epidemiológica $n^{\circ} 38$, terminada em 20/09/97, demonstra que apenas três estados não apresentavam casos de sarampo confirmados laboratorialmente. Tendo em vista essa situação, são recomendadas estratégias a serem adotadas em todas as unidades federadas, visando o controle da epidemia no país.

\section{Histórico}

O sarampo passou a ser doença de notificação compulsória nacional em 1968. Durante muitos anos, foi uma das principais causas de morbidade e mortalidade na infância, principalmente nos menores de $\mathrm{l}$ ano de idade ${ }^{1,2,3}$.
A doença comportava-se de forma endêmica no País, ocorrendo epidemias a cada 2 ou 3 anos ${ }^{2,3}$. A vacina contra o sarampo foi introduzida no Brasil na década de 1960, e sua utilização na saúde pública foi resultante de iniciativas de alguns governos estaduais que, de acordo com

Gráfico I - Sarampo: Estratégias de controle e incidência anual, Brasil, 1967 - 1997*

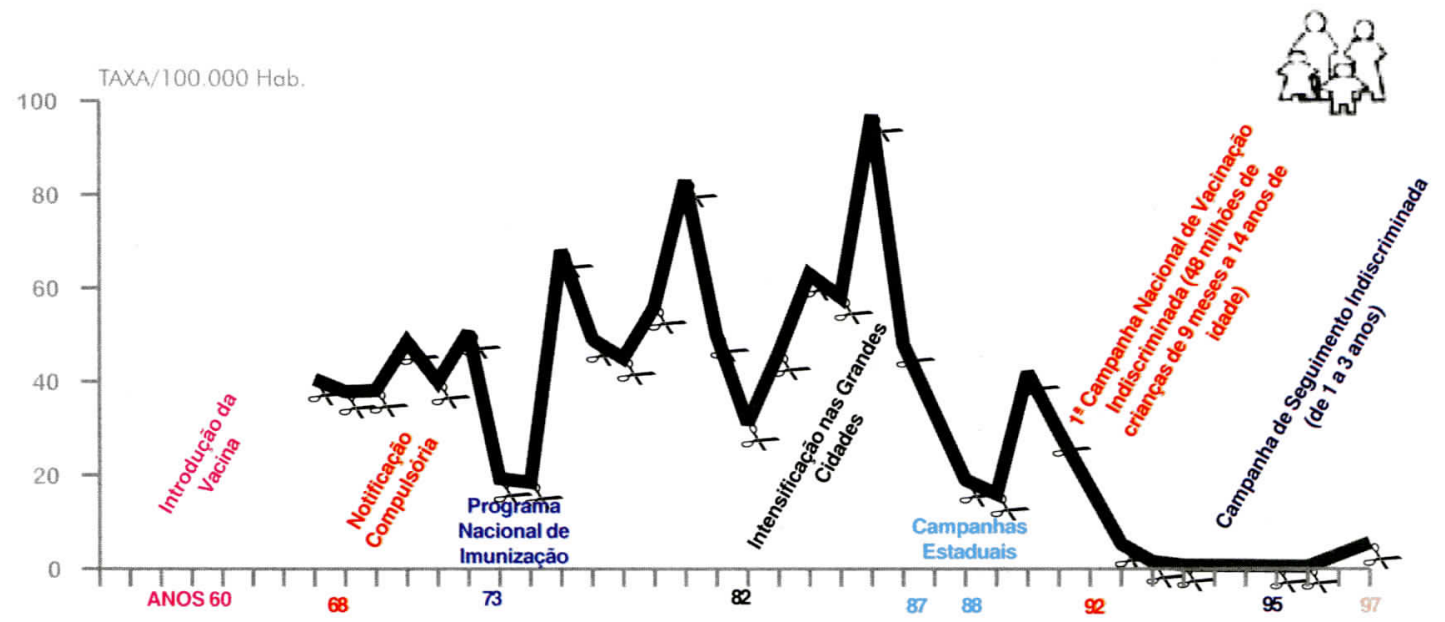

•Dados preliminares, atualizados em 01/10/97. Fonte: GT/SARAMPO/CNDI/CENEPI/FNS/MS

1 Técricas do Grupo de Trabalho de Sarampo/CENEPI/FNS/MS

${ }_{2}^{2}$ Gerente Técnica do Grupo de Trabalho do Sarampo/CENEPI/FNS/MS

${ }^{3}$ Responsável pelo Centro Nacional de Referência Laboratorial para o Sarampo/FIOCRUZ/MS

${ }^{4}$ Consultar da Organizaçăo Pan-Americana da Saúde no Brasil

IESUS, V(1), Jan/Mar, 1997. 
suas possibilidades, importavam o imunobiológico no mercado internacional, embora de forma descontínua ${ }^{4,5}$.

Em 1973, foi criado o Programa Nacional de Imunizaçóes - PNI, com os objetivos principais de organizar, implementar e avaliar as ações de imunizaçáo em todo o país 4,5 .

Nesse mesmo ano e em 1974 foram realizadas campanhas de vacinação em áreas urbanas de vários estados. Essa estratégia foi logo substituída pela valorização dos serviços de rotina e expansáo dos serviços básicos de saúde".

No início da década de 80 , em razão das dificuldades de se atingir, na rotina do PNI, as coberturas vacinais mínimas necessárias para o controle das doenças, foram realizadas campanhas de vacinação em locais onde eram encontradas baixas coberturas vacinais ${ }^{4,5}$.

Em 1986, ano que apresentou a maior epidemia da década, foram notificados 129.942 casos de sarampo, o que representou uma incidência de 97,7 por 100.000 habitantes.

Campanhas de vacinação em massa contra o sarampo foram realizadas em 1987 no Estado de São Paulo e em 1988 no do Paraná, visando o controle e a eliminação da doença. Apesar da introdução da vacina no país, do incremento paulatino das coberturas vacinais $\mathrm{e}$ das campanhas, foram observadas epidemias a cada 2 ou 3 anos, apresentando uma incidência de 42 por 100.000 hab. no final da década de $90^{6}$.

A experiência adquirida com as Campanhas da Erradicaçáo da Varíola no mundo e com a Campanha para Erradicação da Circulação do Poliovírus Selvagem Autóctone na região das Américas motivou a aplicação de princípios técnicos, de estratégias de controle $\mathrm{e}$ de vigilância epidemiológica das doenças evitáveis por imunização. Somando-se a isso, algumas experiências bem sucedidas de controle e eliminação do sarampo em alguns locais como, por exemplo, Cuba, países de língua inglesa do
Caribe e o Estado de São Paulo, evidenciaram também a exeqüibilidade do controle $e$ eliminação do sarampo ${ }^{1,3}$.

Visando atingir essa meta, o Brasil definiu a extinçáo da doença como prioridade da sua política de saúde implantando, em 1992, o Plano Nacional de Eliminação do Sarampo. O Plano teve como estratégia o desenvolvimento de açōes técnicas determinadas, a saber ${ }^{3,6}$ :

- vacinação da populaçáo entre 9 meses e 14 anos de idade, independentemente da situaçáo vacinal anterior ou história prévia da doença ("catch-up");

- manutenção de, no mínimo, $95 \%$ de cobertura vacinal para os menores de $\mathrm{I}$ ano de idade, na rotina do Programa Nacional de Imunizaçōes;

- organização de campanhas de seguimento ("follow-up") entre 3 e 5 anos, para eliminar o número acumulado de crianças suscetíveis, ou seja, que nunca foram vacinadas, nessas coortes de nascidos vivos;

- vigiláncia epidemiológica intensiva para os casos suspeitos na comunidade;

- diagnóstico laboratorial etiológico de todo caso suspeito notificado;

- capacitação de pessoal para o desenvolvimento das atividades do Plano (vigilância epidemiológica, imunizações e diagnóstico laboratorial) em nível nacional e;

- campanhas de divulgação, com o objetivo de sensibilizar a população em geral, a classe política e os profissionais de saúde.

O marco inicial do Plano deu-se com a realização da Campanha Nacional de Vacinação, no período de 22 de abril a 25 de maio de 1992, na qual foram vacinadas 48.023 .657 crianças $\mathrm{e}$ adolescentes, tendo sido atingida uma cobertura de $96 \%$. Em relação às macrorregiões, as coberturas vacinais foram: $99 \%$ para o Norte, 95\% para o Nordeste, $96 \%$ para o Sudeste, 95\% para o Sul e $99 \%$ para o Centro-Oeste. Em relação aos municípios, $68 \%$ alcançaram coberturas vacinais iguais ou maiores que $95 \%$, sendo que alguns atingiram coberturas equivalentes a $100 \%$. Porém, $32 \%$ dos 
municípios ficaram com coberturas vacinais abaixo de $95 \%$ (Gráfico I) ${ }^{3,6}$.

O impacto das açóes do Plano foi imediato. Após a Campanha Nacional de Vacinação, houve uma redução de $81 \%$ no número de casos notificados: de 42.934 casos em 1991 para 7.934 casos em 1992. Desde então, apenas $32 \%$ dos municípios brasileiros, em média, atingiram, na vacinação de rotina, coberturas satisfatórias para o controle do sarampo (iguais ou maiores que $95 \%$ ), entre os menores de 1 ano de idade. Ou seja, $68 \%$ dos municípios, nos últimos quatro anos, vêm acumulando indivíduos suscetíveis ao sarampo entre as crianças menores de 5 anos. Com base nesses dados, é possível estimar que o acúmulo representa uma coorte de 3.552 .230 crianças suscetíveis nesse grupo etário. Considerandose que a eficácia da vacina contra o sarampo varia entre $90 \%$ e $95 \%$, a esse número de suscetíveis deve ser acrescido o de crianças que tomam a vacina e não ficam imunizadas. Chega-se, dessa forma, a uma coorte acumulada de cerca de 4 milhốes de crianças suscetíveis entre os menores de cinco anos.

Portanto, o segundo momento da estratégia - cobertura satisfatória através de vacinação de rotina - não foi cumprido com êxito, de maneira homogênea, em nenhum dos anos seguintes a $1992^{7}$ (Gráfico II).

Nos anos posteriores à Campanha Nacional de 1992, houve uma importante diminuição do número de casos confirmados por sarampo. A taxa de incidência nos anos de 1991 e 1996 , foi de 28,95 por 100.000 habitantes e de 1,6 por 100.000 habitantes, respectivamente (Gráfico II), verificando-se uma redução de $94,5 \%$.

Com relação à mortalidade, verificouse uma tendência geral à diminuição dos coeficientes entre 1977 e 1995. Nesse período, o ano que apresentou maior coeficiente foi o de 1979, com 3,5/100.000 hab.(3.386 óbitos), e o menor foi registrado em 1995, com 0,04/100.000 hab. (7 óbitos) (Gráfico III). Tal situação pode ser explicada, em parte, pelo aumento das coberturas vacinais que, ao proporcionar proteção aos menores de 5 anos, evitou que os mesmos adoecessem e morressem em função de complicações da doença.

Ocorreu, também, acentuada diminuição da taxa de letalidade nesse mesmo período. No ano de 1978 tal taxa atingiu $5,4 \%$, enquanto em 1995 ela foi de 0,1\% (Gráfico III). No tocante à mortalidade e à letalidade por faixa etária, verifica-se que seguiram a mesma tendência, sendo os menores de 1 ano os mais

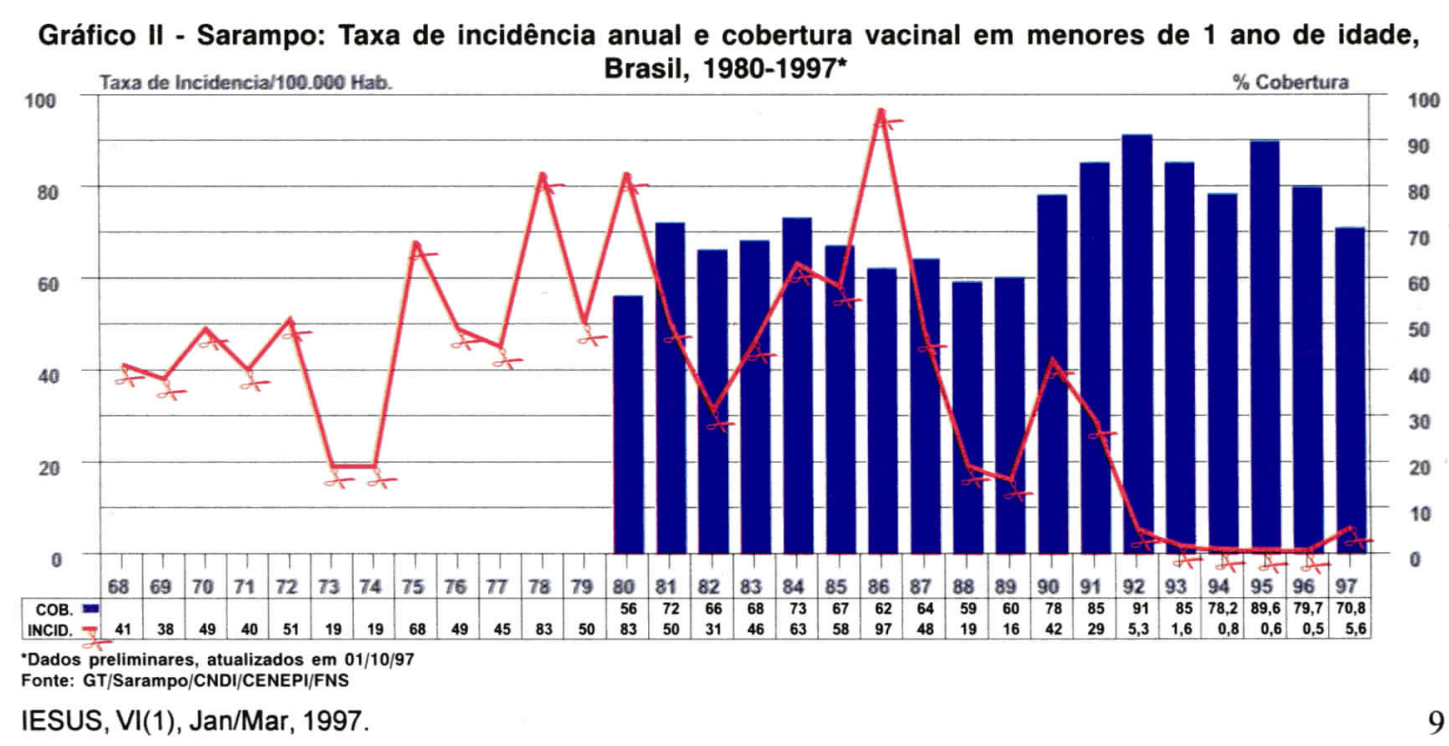


Gráfico III - Sarampo: Coeficiente de mortalidade e taxa de letalidade, Brasil, 1977-1995*

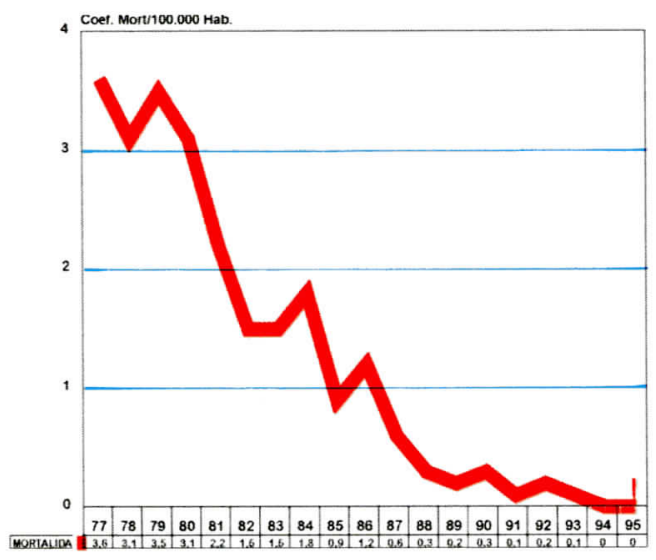

Fonte: GT/Sarampo/CNDI/CENEPI/FNS

atingidos, seguidos dos de 1 a 4 anos e de 5 a 14 anos.

Em setembro de 1994, durante a solenidade de entrega do Certificado de Erradicação da Poliomielite na região das Américas, a decisão tomada na XXIV Conferência Sanitária Panamericana foi a de definir como metal a eliminação do sarampo do Hemisfério Ocidental até o ano $2000^{6}$. Essa meta também foi assumida pelo Ministério da Saúde do Brasil ${ }^{1,6}$.

Com o objetivo de evitar a perda de todo o investimento e dos progressos alcançados com a implantação do Plano e, no intento de manterse o controle da doença até a sua eliminação, a Fundação Nacional de Saúde, após reunião conjunta de seus técnicos do GT-Sarampo e do Programa Nacional de Imunizaçóes com especialistas, assumiu a realização de campanhas de seguimento de vacinação contra o sarampo ("follow-up")

Com base nos dados referentes às coberturas vacinais alcançadas em serviços de rotina nos anos de 1992 a 1994 - que demonstravam um acúmulo de indivíduos suscetíveis na população de $\mathbf{l}$ a 3 anos de idade, por não ter sido atingida uma cobertura vacinal acima de $95 \%$ na maioria dos estados e municípios - decidiu-se pela realização da $1^{\text {a }}$

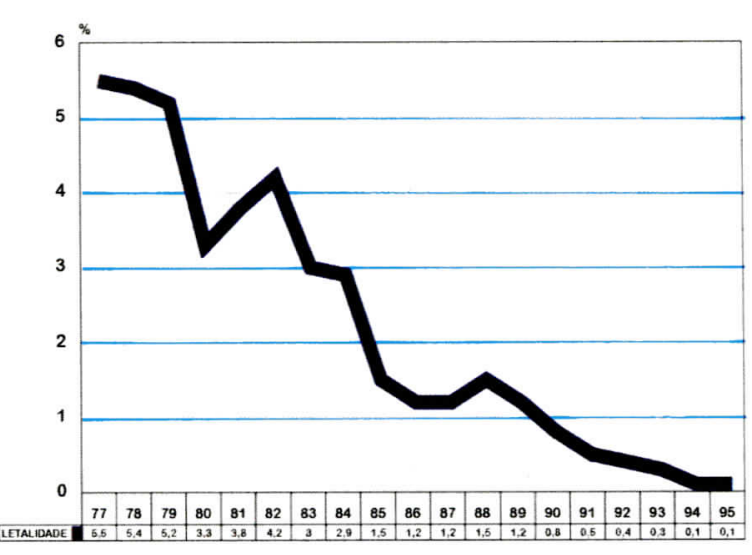

Campanha Nacional de Vacinação de Seguimento contra o Sarampo, de forma indiscriminada para a faixa etária de 1 a 3 anos de idade (Gráfico IV) ${ }^{6}$.

Essa campanha foi realizada no dia 19 de agosto de 1995. A implementação dessa ação, porém, não demonstrou o mesmo desempenho que a realizada no ano de 1992 . A cobertura nacional foi de apenas $77 \%$, não obtendo éxito no alcance da meta proposta e, em São Paulo, essa campanha não foi realizada. As coberturas vacinais na maioria das macrorregióes também ficaram bem abaixo do esperado, sendo: Norte $-67,35 \%$, Nordeste - $75,66 \%$, Sudeste - $76,91 \%$, Sul - 92,9\% e Centro-Oeste - 66,24\%.

Os problemas agravaram-se a partir de 1995, devido a dificuldades no fornecimento da vacina contra a doença para a manutenção da rotina, como resultado dos entraves ocorridos no processo de licitação e dos atrasos na disponibilização da mesma pela indústria nacional.

Nos anos posteriores à implantação do Plano, à exceção de 1995, foram identificados pequenos surtos nos Estados do Paraná (1992), do Rio Grande do Sul (1993) e do Ceará (1992 e 1994), sendo contidos pela intervenção oportuna da Vigilância Epidemiológica através da adoção imediata das medidas de controle 


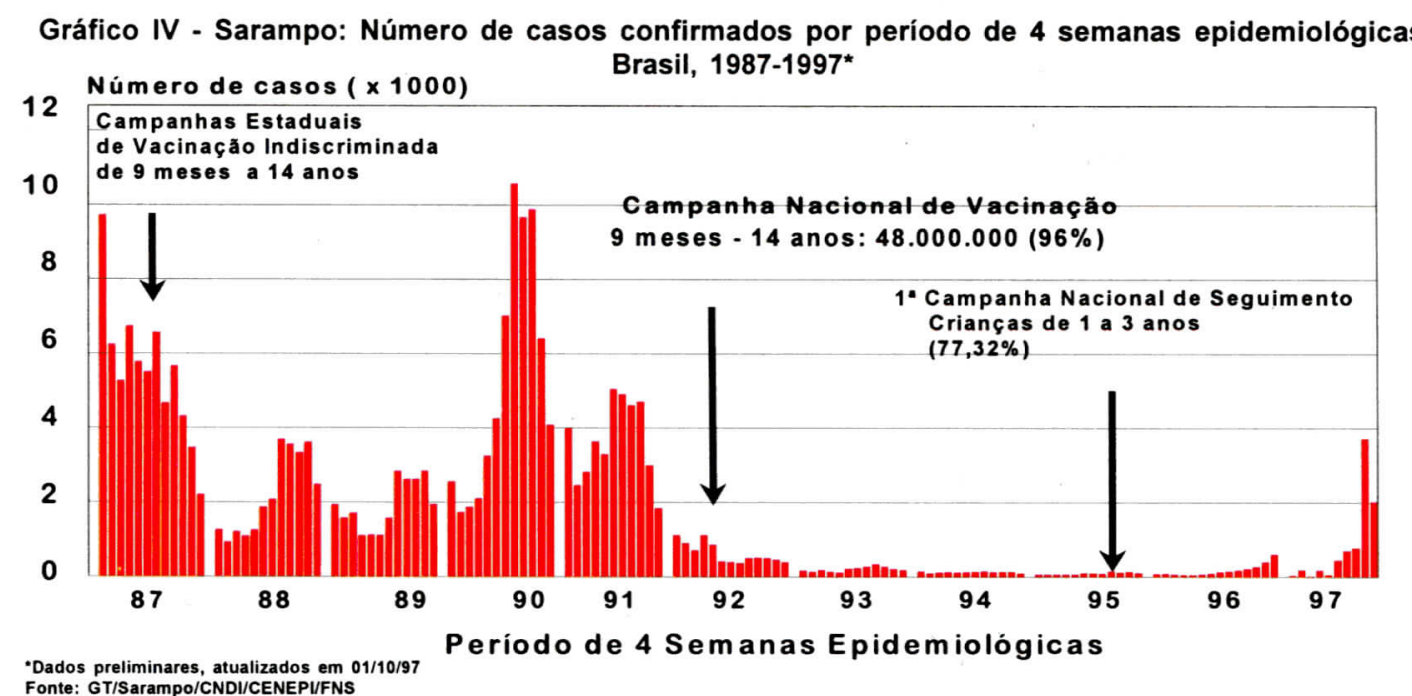

preconizadas pelo Plano de Eliminação do Sarampo. Nesses surtos, mais de $50 \%$ dos casos ocorreram em indivíduos acima dos 15 anos de idade $^{1}$.

Em 1995, foram confirmados laboratorialmente 21 casos em 6 estados, não havendo relação de espaço e tempo dos casos entre si e não tendo sido identificado surtos.

Situação epidemiológica - 1996 e 1997

No primeiro semestre de 1996, foram identificados no país 3 casos importados de sarampo, sendo 2 (irmãos) da Itália que desembarcaram em junho no Rio de Janeiro e em seguida foram para Minas Gerais sendo que o primeiro caso apresentou início do exantema em 23/06/96, e 1 do Japão, que desembarcou no dia 27/04/96 em São Paulo, seguindo para o Mato Grosso, onde adoeceu gravemente devido a complicações, apresentando o início do exantema em $4 / 5 / 96^{7}$.

No segundo semestre de 1996, no mês de setembro, o Estado de Santa Catarina detectou um surto de sarampo, totalizando 24 casos até o mês de dezembro (caso índice com data de início do exantema em 06/09/96). Nesse mesmo mês, o Estado de São Paulo também detectou um surto de sarampo, iniciado a partir de setembro, com o primeiro caso apresentando o início do exantema em 22/09/96 .
Em abril de 1997, o número de casos de sarampo começou a elevar-se em progressão geométrica no Estado de Sáo Paulo, atingindo sobretudo a região metropolitana e apresentando uma maior concentração na capital. A região metropolitana abriga $43 \%$ da população do Estado estimado em um total de 34.655.663 habitantes.

Concomitantemente à elevação do número de casos em São Paulo, foram verificadas, a partir do mês de maio, importações de casos de sarampo provenientes desse Estado em outros estados do país e em outros países. A Bahia e o Ceará registraram casos com confirmação laboratorial, cujas fontes de infecção eram residentes em São Paulo, na região metropolitana ou capital (Gráfico V) ${ }^{6}$.

Em junho, a epidemia expandiu-se rapidamente em São Paulo e começaram a aparecer casos em outros estados das Regióes Sudeste, Nordeste, Norte, Centro-Oeste e Sul.

Até a presente data (semana epidemiológica $\mathrm{n}^{\mathrm{0}} 38$, terminada em $20 / 09 / 97$ ), o Estado de Sáo Paulo registrou a maior concentração dos casos (6.803), seguido da Bahia (397), de Minas Gerais (368 casos ) e do Ceará (323 casos). No País, foram notificados 32.782 casos sendo 8.872 confirmados por laboratório (Gráfico VI). São Paulo e Ceará apresentam a maior incidência: 19,6 e 4,7 por 
100.000 hab., respectivamente. A maioria dos Estados brasileiros, até o presente momento, apresenta uma incidência abaixo de 0,5 por 100.000 hab., sendo que apenas 3 estados não confirmaram casos de sarampo laboratorialmente: Roraima, Acre, e Alagoas
(Mapa I $)^{6,7}$.

Cerca de $55 \%$ dos casos estão ocorrendo entre adultos jovens na faixa etária de 20 a 29 anos, ou seja, uma coorte nascida entre 1968 e 1977, quando os programas de vacinação estavam sendo implementados. A segunda faixa

Gráfico V - Sarampo: distribuição dos casos confirmados por semana epidemiológica (1-40) de
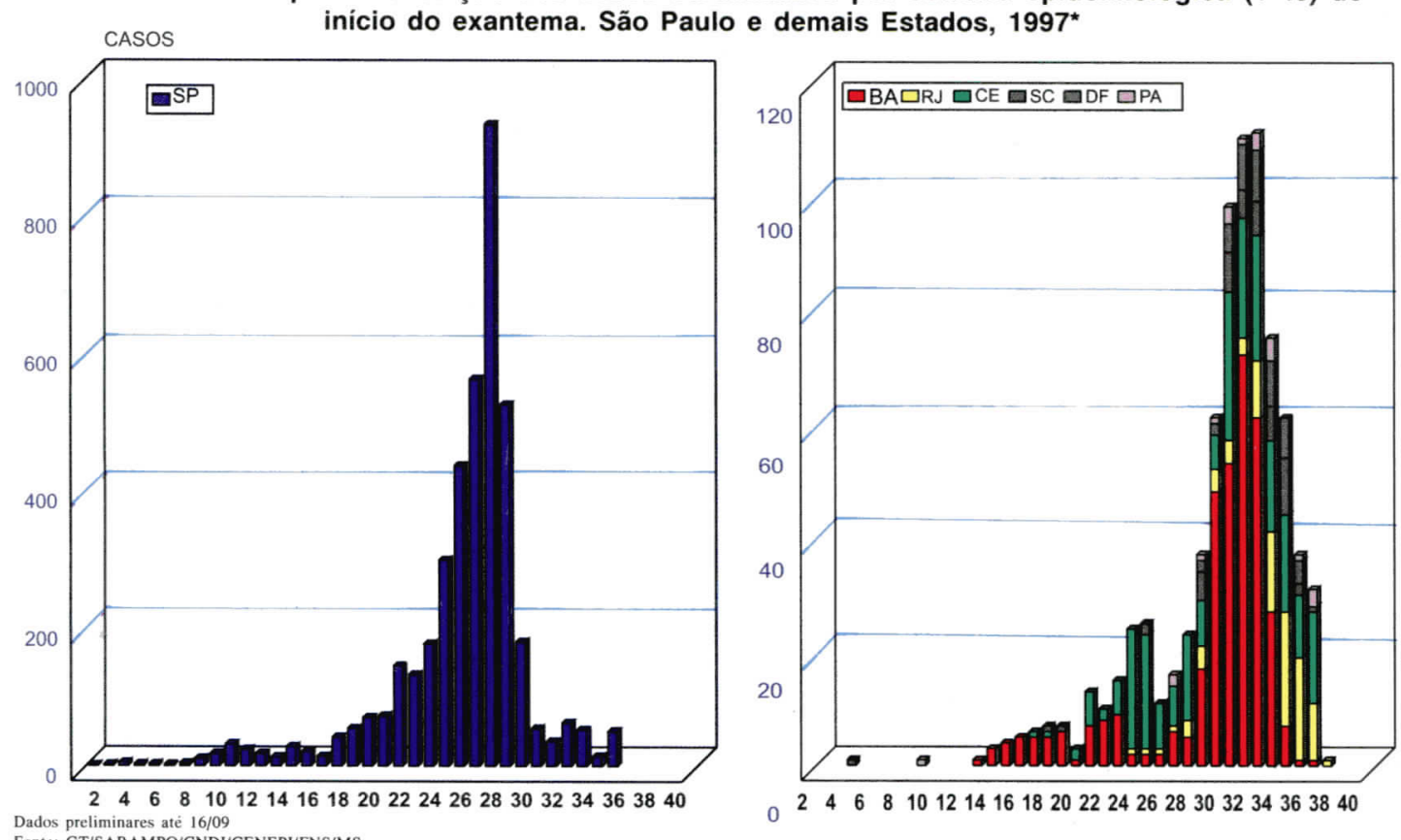
Fonte: GT/SARAMPO/CNDI/CENEPI/FNS/MS

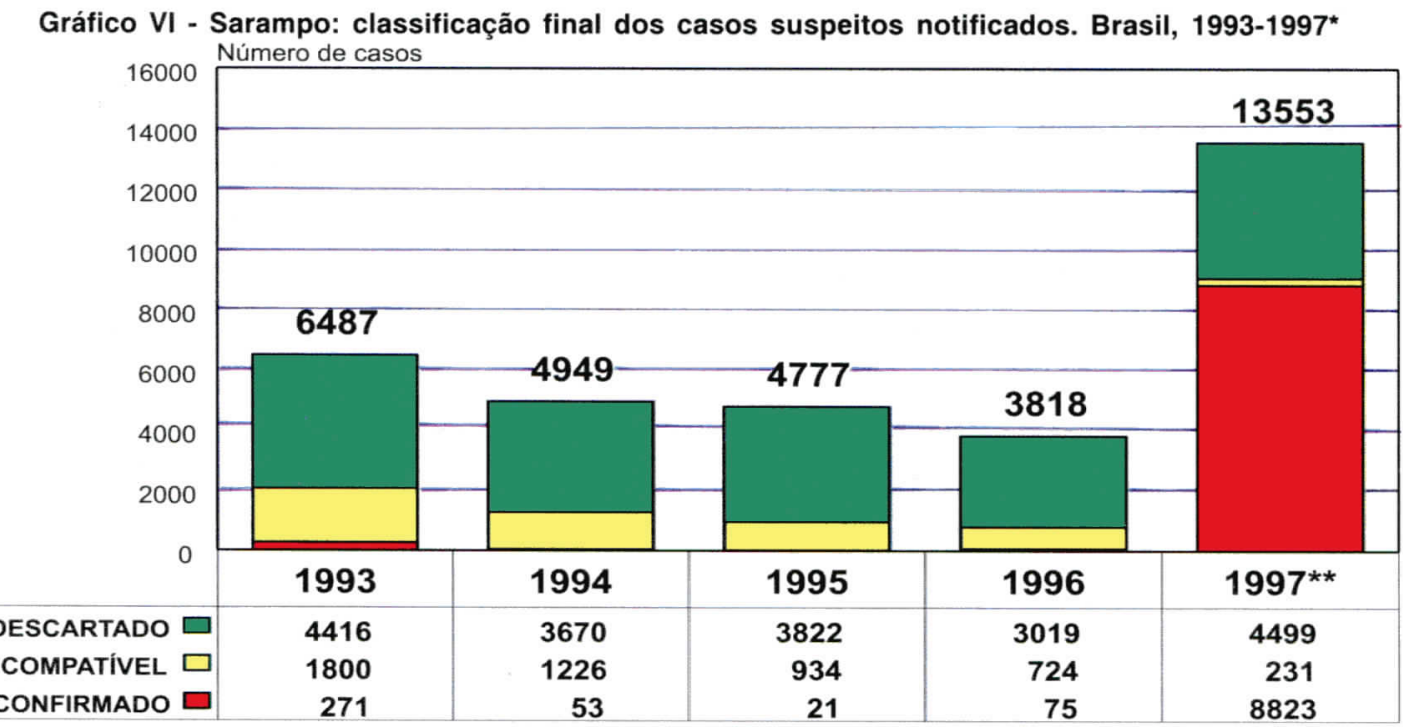

**Aguardando Classificação 19.229 casos. 
de idade que apresenta um percentual maior de casos é a de menores de 1 ano de vida (15\%). A taxa de ataque é também mais elevada nesses mesmos grupos etários: 32,62/100.000 habitantes para os menores de 1 ano e 13,86/ 100.000 hab. para os de 20 a 29 anos de idade, respectivamente (Gráfico VII) ${ }^{6,7}$.

No Estado de São Paulo, até o dia $01 /$ 10/97, foram registrados 11 óbitos: 5 entre os menores de $\mathrm{l}$ ano de vida $(45,4 \%)$ e 2 na faixa etária de $\mathrm{l}$ a 4 anos (18,2\%), e os demais em outras faixas etárias, representando um países identificaram casos de sarampo cuja fonte de infecção foi originada de São Paulo, havendo a ocorrência de casos secundários. Até o presente momento, ocorreram 36 casos no Paraguai, 30 casos no Chile, 10 casos nos Estados Unidos e 03 casos no Peru.

\section{Isolamento viral}

No Brasil, até o início do surto de Santa Catarina, não se tinha identificado o(s) genotipos(s) do vírus do sarampo que circulava(m) no país. Em 1996, por ocasião

Mapa I - Sarampo: Distribuição Geográfica da taxa de incidência dos casos confirmados por estado, Brasil, 1997*

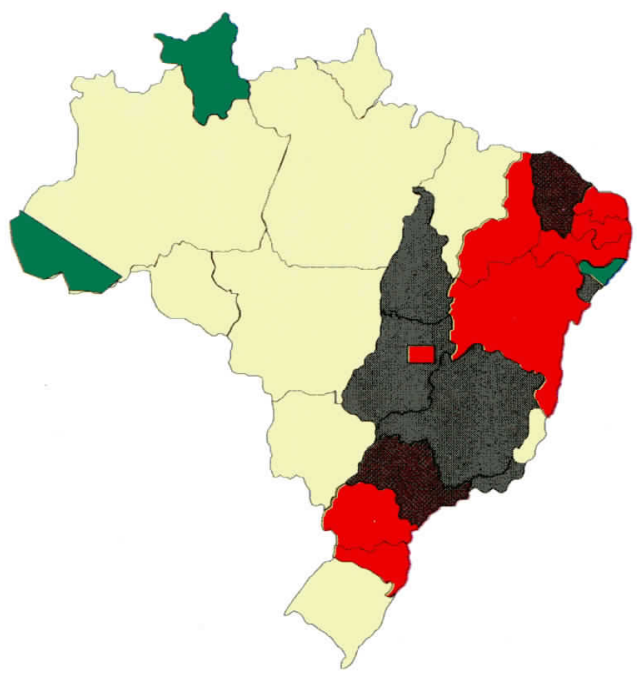

TAXA /100.000 hab.

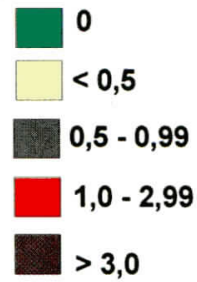

Dados preliminares, atualizado em 01/10/97 Fonte: GT-Sarampo/CNDI/CENEPI/FNS/MS

coeficiente de mortalidade de 0,76 e 0,07 por 100.000 habitantes, respectivamente. Mais 21 óbitos estão sob investigação.

Embora a informação a respeito da situação vacinal dos casos ainda não esteja disponível de forma adequada em âmbito nacional, há indicações de que, em sua maioria, eles estão ocorrendo entre não-vacinados (Gráfico VIII).

Entre maio e setembro de 1997, quatro desse surto, foi possível realizar o isolamento viral em dois casos, com a coleta de espécimes clínicas como sangue, urina e secreção nasofaringe de vários casos suspeitos. $\mathrm{O}$ primeiro isolamento foi derivado da amostra de urina e o segundo, de secreção naso-faringe, coletados entre 2 e 3 dias a partir do início do exantema. A análise genômica dessas amostras mostraram que são pertencentes ao Grupo Genômico V, que atualmente tem sua circulação identificada no 
Gráfico VII - Sarampo: Número e coeficiente de incidência de casos confirmados por faixa etária,

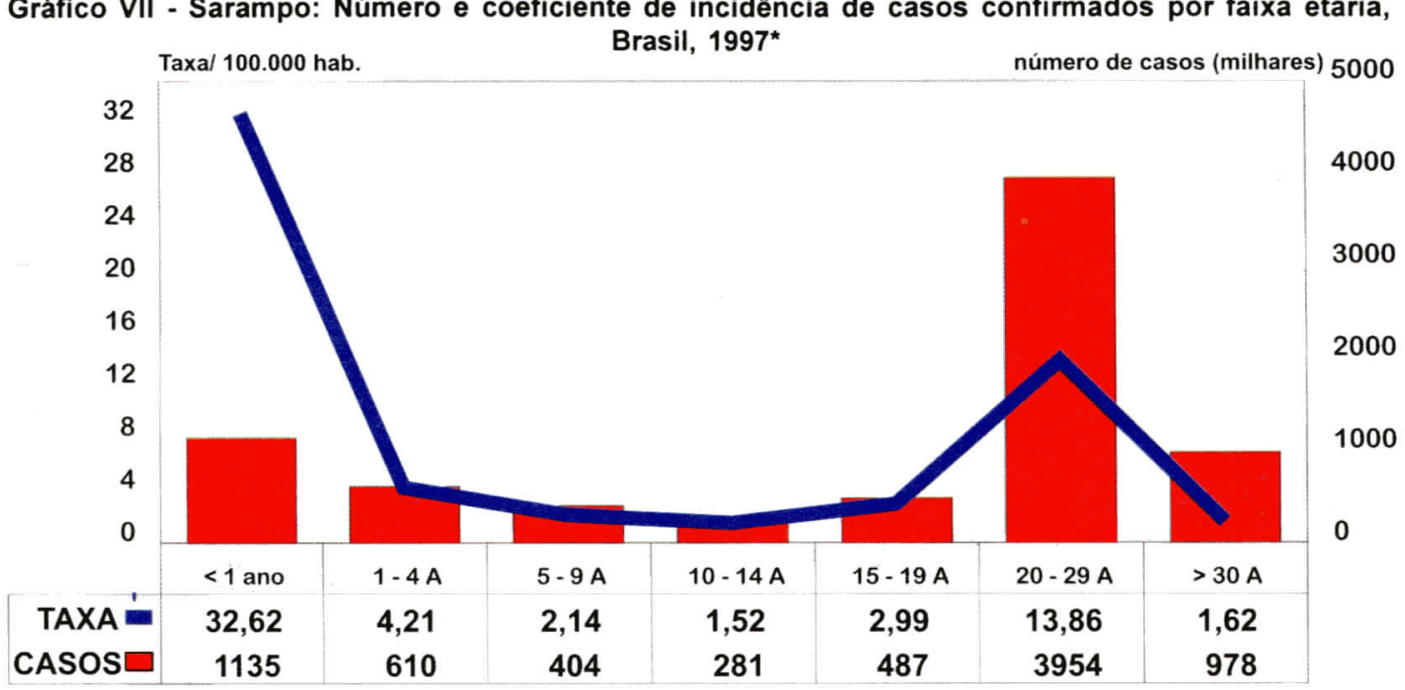

-Dados preliminares, atualizado em 01/10/97

Fonte: GT-Sarampo/CNDI/CENEPI/FNS/MS

Gráfico VIII - Sarampo: Situação vacinal* dos casos confirmados por faixa etária, Brasil, 1997^^

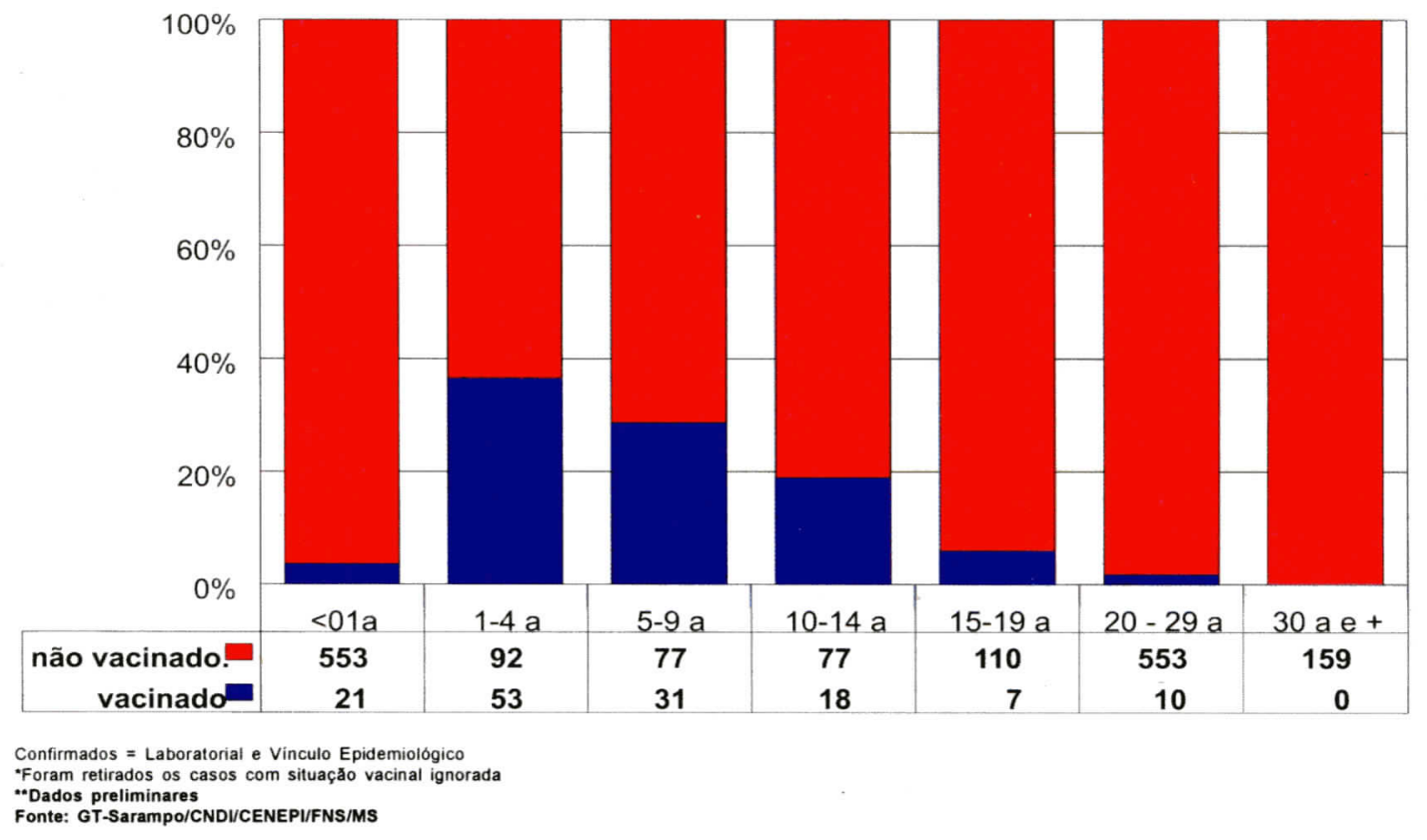


continente europeu ${ }^{8}$.

Ainda em 1996 foi realizada análise genômica a partir de soro sanguíneo, analisado em 3 amostras que tiveram IgM positivo para sarampo, coletadas em casos esporádicos no Estado da Bahia. A análise genômica dessas amostras mostrou que são pertencentes ao Grupo Genômico III, cuja circulação tem sido identificada nos países da Ásia.

No ano de 1997, até o presente momento, foi realizada a análise genômica de 2 amostras de vírus isolados em São Paulo e 3 amostras no Rio de Janeiro, revelando que as mesmas pertencem ao genotipo IV, que nos últimos anos tem circulado na Europa Ocidental.

Esses resultados demonstram que pelo menos três tipos de vírus circularam no País nos anos de 1996 e 1997. Como não havia tal identificação antes do Plano de Eliminação do Sarampo, não se pode afirmar se os surtos ocorreram em funçẫo de importaçōes de outros países ou se esses vírus tem circulação autóctone em nosso país. Daí a importância de realizar-se o mapeamento genotípico em todos os estados que estáo com casos confirmados de sarampo; futuramente, se houverem novas confirmaçốes, poderá ser identificado se essas são decorrentes de importaçōes ou não.

A continuidade dessa análise é fundamental também para que se possa verificar se o surto que está ocorrendo nos demais estados pertencem ao mesmo genotipo de Sáo Paulo ou se está havendo a introdução de outros genotipos no Brasil.

A análise genômica durante surtos e epidemias demonstra a medida do sucesso das estratégias de controle - foi possível verificar que o surto de Santa Catarina permaneceu localizado no próprio Estado.

\section{Estratégias adotadas para controle do surto}

A atual situação epidemiológica do sarampo no Brasil indica a necessidade premente de medidas de controle capazes de proteger, em primeiro lugar, o grupo de maior risco de complicaçóes e óbitos, ou seja, os menores de 5 anos de idade?

As crianças e adolescentes que não foram vacinados na Campanha Nacional contra o Sarampo em 1992, na rotina ou nas campanhas de anos posteriores, são as mais suscetíveis: provavelmente não adquiriram a doença em função da diminuição da circulação do vírus do sarampo em todo o País, após a implantação do Plano de Eliminação do Sarampo.

Como medida fundamental de controle para o enfrentamento desse problema de saúde pública, a recomendação do Ministério da Saúde é a realização de Campanhas de Vacinação, de forma indiscriminada, para a faixa etária de 6 meses a menores de 5 anos de idade (ressaltando que os lactentes de 6 a 8 meses devem receber nova dose da vacina a partir dos 9 meses de vida, conforme calendário oficial do PNI). Essa medida, ao mesmo tempo em que protege o grupo onde podem ocorrer os casos mais graves, torna factível a obtençáo de altas coberturas vacinais (>95\%), imprescindíveis para impedir a circulação viral. Por outro lado, a medida também beneficia o conjunto da população de suscetíveis, como ocorreu em São Paulo no início da década, quando a vacinação nesse grupo etário proporcionou redução significativa na incidência da doença entre adultos. A redução da idade para os 6 meses é imprescindível diante da ocorrência de casos "precoces", que potencialmente apresentam maior gravidade.

Em São Paulo, essa medida já foi posta em prática, com pleno êxito, no primeiro dia da Campanha de Multivacinação (16 de agosto), com a expectativa de que detenha a progressão do surto já a partir do final de setembro/início de outubro. Nos outros dois estados com maior incidência, Bahia e Ceará, também foi tomada essa medida, mas com a vacina tríplice viral.

A experiência internacional também reforça essa medida como prioritária, em casos de surto semelhantes ao observado em nosso país, tendo sido referendada pelo Comitê Assessor em Imunizaçóes da Organização Panamericana de Saúde (OPAS), reunido na Guatemala, no mês de setembro de $1997^{9}$. 
Para as crianças e adolescentes de 5 a 14 anos de idade, a recomendação é a vacinação de forma seletiva, tanto nos serviços de rotina quanto no segundo dia da Campanha de Multivacinação, em 25 de outubro. Recomendase também a deteç̧ão de não-vacinados nesse grupo etário nas escolas (públicas e privadas), utilizando-se os professores para referência de vacinação nas unidades de saúde e priorizando os municípios onde há casos confirmados.

A adoçáo dessas estratégias é fundamental: ao se atingir coberturas vacinais mais homogêneas em todo o País para a população menor de 5 anos e ao se identificar as crianças e adolescentes até 15 anos que ainda não foram vacinados, poderá criar-se uma imunidade de grupo e, conseqüientemente, interromper-se a circulação do vírus nessa população.

Para a faixa etária acima dos $\mathbf{1 5}$ anos e sobretudo nas pessoas maiores de 20 anos de idade, com a segunda maior taxa de incidência, as experiências recentes em nosso país mostram que a realização de campanhas de vacinaçáo indiscriminada contra o sarampo não têm alcançado coberturas vacinais significativas como medida de proteção coletiva das populaçóes. As coberturas médias têm sido em torno dos $20 \%$, mesmo com ampla mobilização e divulgaçăo da mídia - bastante abaixo da cobertura vacinal exigida para haver impacto na diminuição do número de casos, de no mínimo $95 \%$. Esses dados são compatíveis com a experiência anterior em nosso próprio país e no exterior, onde apenas em situações muito excepcionais se consegue obter altas coberturas vacinais entre adultos. Assim, tal estratégia, além de muito provavelmente repetir as coberturas ineficazes, poderia significar um desperdício imenso de recursos materiais e humanos, protelando as medidas que podem realmente deter o surto, além de almejar objetivos que a realidade não sugere que possam ser alcançados ${ }^{7}$.

Outra questão a ser considerada é que a suscetibilidade para o sarampo na população acima de 20 anos é baixa. Resultados preliminares de estudos de prevalência de anticorpos antisarampo para o grupo etário de 20 a 29 anos, realizados em um banco de sangue de São Paulo (localidade que apresenta a maior incidência do país, 37,77 por 100.000 hab.) sugerem que essa suscetibilidade está em torno de apenas 3 a 5\%. Não justifica, portanto, a realização de uma campanha de vacinação em massa para tentar, com pouca chance de êxito, atingir essa pequena parcela da população. A realização desse estudo em outras capitais está sendo proposta para que se possa avaliar se esse perfil sorofásico é identificado em outras localidades?

A melhor estratégia de vacinação para o grupo etário acima dos 15 anos é aquela que define os indivíduos, áreas ou situações de maior risco. A ocorrência de casos de sarampo precisa ser acompanhada por açóes de vigilância epidemiológica que forneçam informações detalhadas capazes de localizar territorialmente, ou em determinados grupos profissionais, a existência de suscetíveis que possibilitem a circulação viral ${ }^{3,7}$.

Essa atuação poderá identificar, entre outras situaçóes:

- favelas, com concentração de migrantes procedentes de localidades com baixas coberturas vacinais;

- zonas rurais onde os ciclos da doença são mais espaçados;

- grupos específicos tais como trabalhadores de construção civil e profissionais de saúde;

- trabalhadores em fábricas, em áreas de colheitas de safras, em acampamentos de 
"sem terra";

- estudantes em escolas, universidades e alojamentos.

Esse mapeamento, com base nos dados epidemiológicos, indicará onde deve ser realizada, de maneira ativa e orientada, uma ação de vacinação capaz de obter índices de cobertura nos níveis necessários para se obter proteção coltiva?

Uma vez constatado que há casos de sarampo confirmados laboratorialmente, não há necessidade de coleta de amostra de sangue para todos os casos suspeitos: havendo a identificação da fonte de infecção, os mesmos poderão ser confirmados por vínculo epidemiológico. Porém, em alguns casos a coleta de amostra de sangue deverá ser realizada obrigatoriamente ${ }^{7}$ :

- toda criança menor de 1 ano, independentemente da situação vacinal;

- todo caso suspeito vacinado, com idade até 19 anos;

- toda pessoa hospitalizada com suspeita de sarampo, independentemente da idade ou situaçăo vacinal.

Deverá também ser realizada a coleta material para isolamento de vírus de, no mínimo, 6 casos suspeitos de sarampo, que sejam contato de casos confirmados laboratorialmente (conforme instruçōes das Diretrizes do Plano de Eliminação do Sarampo) em pelo menos uma localidade de cada Estado (ex.: capital ou cidade próxima ao LACEN) ${ }^{10}$.

\section{Ações preconizadas}

Com o objetivo de determinar estratégias para o controle do sarampo no País, foi realizada uma reunião em Brasília, nos dias 23 e 24 de setembro de 1997, com os Coordenadores Estaduais de Imunizações, a equipe do Programa Nacional de Imunizaçóes/FNS, os membros do GT/Sarampo/CNDI/CENEPI/ FNS e o Diretor do CENEPI/FNS, na qual foram definidas as seguintes condutas a serem adotadas nas Unidades Federadas ${ }^{7}$ :

\section{1 - Realizar Campanha de Vacinação em} menores de 5 anos de idade:

Em 23 Estados será realizada uma campanha de vacinação indiscriminada com vacina contra o sarampo (ou seja, independente do estado vacinal prévio) nas crianças de 6 meses até 4 anos completos. Em 4 Estados (BA, CE, PI e RS) será introduzida a vacina tríplice viral devendo ser vacinada a população de 1 a 11 anos de idade, de forma indiscriminada.

Essa vacinação com vacina contra o sarampo tríplice viral deve ser iniciada juntamente com a Campanha Nacional de Multivacinação. Em função da necessidade de serem capacitados recursos humanos para a realização dessa Campanha e de ser necessário uma boa divulgação nos meios de comunicação e uma ampla discussão com todos os setores da sociedade envolvidos nessa estratégia, decidiuse adiar a Campanha Nacional de Multivacinação para o dia 25/10/97. É importante monitorar as coberturas alcançadas pelos municípios e, aqueles que não atingiram uma cobertura vacinal acima de $95 \%$ deverão estender a campanha por mais tempo.

A segunda recomendação visa a vacinação nas áreas ou grupos de risco identicas durante a investigação de casos e surtos e inclue:

1 - Vacinar os escolares da rede pública e privada:

Estratégia de Vacinação - Seletiva;

Faixa Etária - de 5 anos a 14 anos de idade.

2 - Realizar vacinação para os contatos de casos suspeitos ou confirmados (Bloqueio): 
Estratégia de Vacinação - Seletiva;

Faixa Etária - a partir de 6 meses, sem limite superior;

Local - em domicílios e em instituições fechadas (universidades, creches, escolas, canteiros de obras, quartéis, empresas, fábricas, orfanatos, etc).

\section{3 - Identificar áreas de risco e realizar} vacinação de forma ampliada:

Estratégia de Vacinaçáo - Seletiva;

Faixa Etária - de 6 meses até 40 anos de idade

Local - de acordo com o mapeamento geográfico das áreas com aumento de casos.

\section{4 - Vacinar os profissionais dos serviços de} saúde (incluindo pessoal apoio e administrativo):

Estratégia de Vacinação - Seletiva

Faixa Etária - Priorizar até os $\mathbf{4 0}$ anos

\section{Considerações finais}

A introdução da vacina contra o sarampo em larga escala no final dos anos 60 proporcionou ao longo das últimas duas décadas um progressivo declínio da incidência e da mortalidade por sarampo em todos os continentes. Apesar disso, o sarampo ainda não foj erradicado em nenhum país do mundo e a Organizaçáo Mundial de Saúde estima que ocorram anualmente 1 milhão de mortes e aproximadamente $\mathbf{4 0}$ milhões de casos de sarem po no mundo"l. A alta infectividade do vírus causador da doença e o rápido acúmulo de suscetíveis têm demonstrado que o controle ou eliminação da doença precisa de múltiplas estratégias programáticas.

As estratégias introduzidas na maioria dos países da Região das Américas no início dos anos 90 buscaram combinar uma campanha indiscriminada ("catch-up") entre os menores de 15 anos com uma cobertura vacinal alta de rotina entre os menores de 1 ano, e a realização de uma campanha de seguimento ("follow-up") para todos os menores de 5 anos, a cada 4 anos. Tais estratégias obtiveram resultados bastante positivos, de tal forma que no ano de 1996 observou-se aproximadamente 2000 casos confirmados em cada Região. Mais de 1000 casos foram notificados no Canadá e Estados Unidos

No Brasil e apesar de nunca ter atingido média nacional satisfatória para a cobertura vacinal de rotina (>95\%), a implementação das estratégias de eliminação como a Campanha de Vacinação em menores de 15 anos no ano de 1992, propiciou a redução significativa da incidência e da mortalidade por sarampo durante o período de 1992 até 1995, quando se registrou apenas 21 casos confirmados laboratorialmente de mais de $\mathbf{4 0 0 0}$ casos suspeitos notificados e investigados.

A combinação das permanentes coberturas vacinais de rotina com índices insuficientes $(<95 \%)$ e, o baixo resultado da campanha de seguimento nas crianças menores de 4 anos, em 1995, propiciaram o acúmulo de suscetíveis necessários para explicar pelo menos, parcialmente, que o atual surto atinge todo o país com exceção do Acre e Roraima. Outra questão a ser analisada é o fato de ter encontrado uma proporção grande (acima de 50\%) de casos nos adultos de 20 a 29 anos. A rápida urbanização, com intenso fluxo migratório desse grupo populacional parcialmente suscetível do interior do país para os grandes centros urbanos como São Paulo e Rio de Janeiro poderia contribuir para explicar o surto que inclue mais de 10.000 casos confirmados somente em São Paulo.

Várias pesquisas estão sendo promovidas para obter melhores explicaçōes sobre a transmissão atual do vírus do sarampo. Em nove Estados (SP, MG, CE, BA, PE, RS, PR, PA e DF) estão sendo realizados inquéritos de soroprevalência de anticorpos específicos $\operatorname{Ig} G$ contra o sarampo na faixa etária de 20 a 29 anos. Também será realizado um estudo de caso controle para confirmar a hipótese de que adultos jovens, migrantes provenientes de áreas de baixa transmissão no passado, formam um importante 
elemento na transmissão do vírus.

A situação é preocupante e demanda um esforço concentrado dos serviços de saúde nos âmbitos federal, estadual e municipal, atuando imediatamente na identificação de casos suspeitos $\mathrm{com}^{7}$ :

- coleta de sorologia em tempo hábil (até 28 dias após o início do exantema);

- $\quad$ adoção das medidas de controle (busca ativa de novos casos e realizaçáo de bloqueio vacinal);

- conclusão do diagnóstico sorológico em até 9 dias;

- $\quad$ encerramento dos casos em até 15 dias;

- acompanhamento e análise dos dados epidemológicos da evolução da doença;

- $\quad$ envio dos dados aos níveis superiores;

- divulgação dos dados para a obtenção de apoio político e o envolvimento dos diversos setores da sociedade civil organizada que possam auxiliar no controle da epidemia.

\section{Bibliografia}

1. Santos, E.D. O Perfil Epidemiológico do Sarampo no Brasil de 1968 a 1995. (Monografia de conclusão do Curso de Especialização em Saúde Coletiva da UNB), 1997.

2. Risi, J. B. Jr.. Control of Measles in Brasil. Review of Infectious Diseases. Chicago. v. 5, n. 3. May - June, 1983.

3. Silva, L. P. Erradicação do sarampo: uma possibilidade real? Revisão crítica da teoria e das estratégias de eliminação. 1993. 200 p. (Tese de mestrado da Escola Nacional de Saúde Pública).

4. Brasil. Ministério da Saúde. Fundação Nacional de Saúde. Centro Nacional de Epidemiologia. Relatório interno do Programa Nacional de Imunizaçóes, não publicado, 77 p., 1992.

5. Brasil. Ministério da Saúde. Secretaria de Açōes Básicas de Saúde. Documento interno, não publicado, 1985.

6. Brasil. Ministério da Saúde. Fundação Nacional de Saúde. Centro Nacional de Epidemiologia. Plano Nacional de Controle e Eliminação do Sarampo (versão preliminar 2). Brasília, 1997.

7. Brasil. Ministério da Saúde. Fundação Nacional de Saúde. Centro Nacional de Epidemiologia. Documento Interno, 1997.

8. Programa Ampliado de Imunizacion. Sarampión en Brasil? Un caso autóctono o importado? Boletin Informativo - PAI, Año XIX, n. 4, febrero, 1997.

9. OPAS - XII Reunião do Grupo Técnico Assessor do Programa Ampliado de Imunizaçōes, Guatemala, Setembro, 1997.

10.Brasil. Ministério da Saúde. Fundação Nacional de Saúde. Centro Nacional de Epidemiologia. Diretrizes Básicas de Eliminação do Sarampo - Guia de Campo (mimeo), 1997.

11. Programa Ampliado de Imunizaçăo. Erradicación Mundial del Sarampión: Meta 2010. Boletim Informativo PAI, ano XVIII n. 4, 1996. 